\title{
MUDANÇAS DAS ROTINAS FAMILIARES NA TRANSIÇÃO INESPERADA POR DESASTRE NATURAL a
}

\author{
Family routines changes in the unexpected transition due to natural disasters \\ Cambios sobre las rutinas familiares en la transición inesperada por desastre natural
}

Gisele Cristina Manfrini Fernandes ${ }^{1}$

Astrid Eggert Boehs ${ }^{2}$

\section{RESUMO}

Desastres naturais são eventos disruptivos às rotinas e rituais familiares e promovem mudanças significativas na vida e na saúde. 0 objetivo deste artigo foi discutir as rotinas diárias ao longo das trajetórias na transição familiar pela ocorrência de um desastre natural ocorrido em uma área rural. Trata-se de um estudo qualitativo de múltiplos casos, realizado com seis famílias com crianças. Os dados foram coletados em 2010, com técnicas de observação participante, entrevista narrativa, genograma, ecomapa e 0 calendário de rotinas familiares. Foi feita a análise das narrativas, e os resultados revelaram a mudança nas rotinas e rituais nas trajetórias entre o pré, o pós-desastre e atualidade. A transição abrupta gerou reações estressantes, afetando a saúde dos membros. São necessários mais estudos sobre a saúde no pós-desastre que contribuam ao conhecimento, ao ensino e à prática do cuidado de enfermagem, especialmente na estratégia de saúde da família.

Palavras-chave: Enfermagem familiar. Saúde da família. Desastres naturais. Acontecimentos que mudam a vida.

\begin{abstract}
Natural disasters are disruptive events to the family routines and rituals, and they promote significant changes in life and health. The aim of this article is to discuss daily routines along with the trajectories in a family transition, due to a natural disaster occurred in a rural area. It is a qualitative study of multiple cases conducted on six families with children. Data were collected, in 2010, with participant observation techniques, narrative interview, genogram, eco-map and the family routines calendar. Narratives analysis have been performed and results have revealed changes in routines and rituals in the trajectories, between the pre-post disaster and nowadays. The abrupt transition has generated stressing reactions, affecting the members' health. Further studies on health are needed in the post-disaster, in order to contribute for knowledge, teaching and practice on nursing care, especially, within the family health strategy.
\end{abstract}

Keywords: Family nursing. Family health. Natural disasters. Life change events.

\section{Resumen}

Los desastres naturales son eventos disruptivos a las rutinas y rituales familiares y promueven cambios significativos en la vida y en la salud. El objetivo de este artículo es discutir las rutinas diarias a lo largo de las trayectorias en la transición familiar debido a un desastre natural ocurrido en un área rural. Se trata de un estudio cualitativo de múltiples casos, realizado con seis familias con niños. Los datos fueron obtenidos en 2010, con técnicas de observación participante, entrevista narrativa, genograma, ecomapa y el calendario de rutinas familiares. Se realizó un análisis de las narrativas y los resultados revelaron cambios en las rutinas y rituales, en las trayectorias entre el pre y el post desastre y la actualidad. La transición abrupta generó reacciones estresantes, afectando la salud de los miembros. Se hace necesario más estudios sobre la salud en el post desastre, que contribuyan al conocimiento, enseñanza y práctica del cuidado de la enfermería, especialmente en la estrategia de salud para la familia.

Palabras claves: Enfermería de la Familia. Salud de la familia. Desastres naturales. Acontecimientos que cambian la vida.

${ }^{1}$ Enfermeira. Doutora em Enfermagem pelo Programa de Pós-graduação em Enfermagem, da Universidade Federal de Santa Catarina (PEN/UFSC). Membro

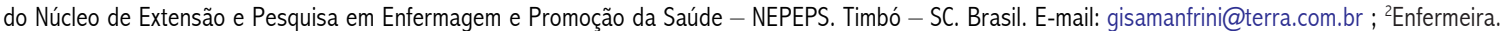
Doutora em Enfermagem. Professora do Departamento de Enfermagem e Programa de Pós-Graduação em Enfermagem da UFSC. Coordenadora do NEPEPS. Florianópolis - SC. Brasil. E-mail: astridboehs@hotmail.com 


\section{INTRODUÇÃO}

Desastres naturais podem ser especialmente caracterizados por violentos eventos como as enchentes, as inundações, os furacões ou os terremotos, os quais podem ser traumáticos à vida e à saúde de crianças e jovens, mas que também têm potencial assustador para os adultos ${ }^{1}$.

Estudos apontam que os efeitos de uma crise pósdesastre aparecem inicialmente na estrutura típica diária², o que é sentido sobretudo pelas crianças e adolescentes, uma vez que as rotinas familiares das quais dependem são afetadas, as tarefas e as funções para o funcionamento familiar são modificadas e diversas reações emocionais são experienciadas pela família de uma maneira integral ${ }^{3,4}$. Contudo, a interrupção das rotinas diárias necessita de um tempo para recuperação após o desastre natural, pois trata-se de um processo que, em si mesmo, implica múltiplas mudanças de vida. Além disso, as adversidades presentes na transição do pós-desastre podem interferir mais diretamente na saúde de alguns de seus integrantes, particularmente das mães que assumem o compromisso pelo bem-estar familiar e as funções de cuidado ${ }^{5,6}$. Para ajudar essas famílias, é importante que os profissionais de saúde tenham habilidades para fornecer o suporte adequado e continuidade nos cuidados à saúde, estabelecendo certa previsibilidade dentro da família e ajudando-a no restabelecimento das rotinas?.

A enfermagem é uma das profissões mais envolvidas no atendimento aos afetados em desastres naturais, cujo enfoque maior tem sido dado às ações de urgência e emergência na resposta a tais eventos, e no planejamento hospitalar. Entretanto, a Organização Panamericana da Saúde (OPAS) e a Organização Mundial da Saúde (OMS) têm divulgado informações constantes sobre as ações da enfermagem no setor de saúde pública, com ênfase na reestruturação dos serviços/programas de saúde e na recuperação das condições de saúde de populações em situações pósdesastres. Isso se aproxima do foco deste estudo, que está direcionado aos enfermeiros atuantes na Atenção Primária de Saúde (APS), e especificamente na política brasileira da Estratégia de Saúde da Família (ESF), tendo em vista que as ocorrências frequentes de desastres naturais nas várias regiões do país, tanto em cenários rurais quanto urbanos, expressam as necessidades de conhecimento e de preparo profissional numa perspectiva longitudinal da assistência nestas realidades. Contudo, são escassos os estudos brasileiros sobre esta temática dos desastres e praticamente inexistentes na literatura de enfermagem, o que confirma a relevância de explorar este contexto de cuidado. No Brasil, estudos sociológicos ${ }^{8,9}$ têm apresentado contribuições importantes para o conhecimento de diferentes realidades de desastres no país, revelando as implicações socioambientais destes eventos às populações atingidas.

Um referencial teórico sobre Rotinas e Rituais Familiares foi estudado por uma pesquisadora e enfermeira norte-american $\mathrm{a}^{10}$, influenciada por estudos antecessores de outras áreas, que resultaram em um modelo destinado ao cuidado de promoção à saúde de famílias. Rotinas de saúde familiar são padrões dinâmicos de comportamentos relevantes à saúde, que os membros aderem na vida diária e que podem ser revistas, descritas e discutidas pelos membros no espaço doméstico, mesmo que nem todos estejam ativamente engajados. As rotinas familiares não são estáticas, mas evoluem todo o tempo e são influenciadas pelas mudanças no ciclo vital e mediante eventos imprevisíveis ${ }^{10}$. Acredita-se que desastres naturais tenham impacto na organização da vida diária das famílias atingidas, afetando temporariamente ou modificando permanentemente algumas rotinas, o que pode levar a consequências positivas ou negativas à saúde da família e dos indivíduos. Este artigo objetivou discutir as rotinas diárias ao longo das trajetórias na transição familiar pela ocorrência de um desastre natural.

\section{MÉTODO}

Trata-se de uma pesquisa qualitativa, do tipo estudo de múltiplos casos, desenvolvido com seis famílias atingidas no desastre natural, em uma área rural do Sul do Brasil, no ano de 2008.

A coleta de dados ocorreu entre janeiro e setembro de 2010, com início após um ano e um mês do evento, e as famílias foram localizadas em suas moradias com a ajuda da equipe de saúde da família local. A seleção partiu de alguns critérios de inclusão: famílias que residissem na área antes do desastre e que tivessem sido de alguma forma afetadas, com ao menos uma criança de 0 a 12 anos, e que aceitassem participar da pesquisa. Uma breve descrição das características de cada núcleo familiar participante do estudo pode ser visualizada no Quadro 1.

As narrativas foram produzidas em contextos de vida familiar especíificos de cada caso, pois compreendiam fases distintas de desenvolvimento, ${ }^{11}$ como de casais com filhos lactentes, adolescentes e em fase madura (uma das filhas havia se casado e saído da casa dos país), e também situações distintas quanto à vida pós-desastre. Para a obtenção dos dados, foram utilizadas as técnicas de observação participante durante os encontros nos domicílios com registros em diário de campo, a entrevista narrativa improvisada ${ }^{12}$, a aplicação de instrumentos como o genograma, o ecomapa e o calendário de rotinas, que se constituiu em um instrumento construído para os próprios integrantes anotarem suas rotinas diárias e 
semanais. Os dados coletados foram gravados com a devida autorização e transcritos pela pesquisadora. Foram realizados quatro encontros com cada uma das famílias, ao longo dos nove meses de coleta de dados.

A análise das narrativas seguiu os passos orientados por Fritz Schütze, criador do método de entrevista narrativa autobiográfica e de análise de narrativas improvisadas. 0 primeiro passo consiste na análise formal do texto, na qual foram selecionadas todas as passagens narrativas, tomando como referência os indicadores formais de inicialização e finalização de cada segmento. No segundo passo, fez-se a descrição estrutural do conteúdo de cada narrativa anteriormente selecionada, em que foram identificados elementos de interpretação das histórias narradas, denominados estruturas processuais do curso da vida. Para a realização do terceiro passo, denominado abstração analítica, foi preciso um distanciamento dos detalhes do conteúdo de cada segmento narrativo e um olhar para o todo da história, ordenando os segmentos narrativos na sequência das etapas da vida ou do evento narrado, interpretando as expressões abstratas de cada etapa, em relação umas com as outras, com base no referencial teórico e objetivo da pesquisa. 0 quarto passo, ou análise do conhecimento, explorou os componentes não indexados das histórias, que são as passagens narrativas argumentativas, explicações teóricas dos informantes sobre seu curso de vida (experiência no desastre) ou identidade (teorias sobre o "eu"), avaliações comparativas e construções de fundo. É nesta etapa que o pesquisador está mais atento à interpretação dos próprios sujeitos. 0 quinto passo consistiu na comparação contrastiva entre as categorias analíticas encontradas na análise dos diferentes textos de entrevistas de cada família, buscando semelhanças e contrastes que favoreceram a comparação dos casos entre $\mathrm{si}^{12}$.

A pesquisa foi aprovada pelo Comitê de Ética em Pesquisa com Seres Humanos, sob o número 490/2009. Respeitou-se 0 anonimato dos informantes e a participação na pesquisa foi considerada mediante a assinatura do Termo de Consentimento Livre e Esclarecido.

\begin{tabular}{|c|c|c|c|c|}
\hline Composição Familiar & Escolaridade & Ocupação & Renda & Danos \\
\hline $\begin{array}{c}\text { F1: Casal e duas filhas emidade } \\
\text { escolar }\end{array}$ & $\begin{array}{l}\text { Ensino fundamental } \\
\text { incompleto. Estudantes } \\
\text { da } 1^{\mathrm{a}} \text { e } 5^{\mathrm{a}} \text { séries. }\end{array}$ & $\begin{array}{l}\text { Auxiliar de senviços } \\
\text { gerais e agricultor. } \\
\text { Costureira. }\end{array}$ & $\begin{array}{l}2 \text { salários } \\
\text { mínimos. }\end{array}$ & $\begin{array}{l}\text { Destruição total da } \\
\text { moradia e } \\
\text { desemprego. }\end{array}$ \\
\hline $\begin{array}{l}\text { F2: Casal, um filho em idade pré- } \\
\text { escolar, uma filha adotiva em } \\
\text { idade escolar, uma filha } \\
\text { adolescente e uma filha } \\
\text { adolescente casada. }\end{array}$ & $\begin{array}{c}\text { Ensino fundamental } \\
\text { incompleto. Ensino médio } \\
\text { incompleto (adolesc). }\end{array}$ & $\begin{array}{l}\text { Pedreiro e do lar. } \\
\text { Costureiras (adolesc) }\end{array}$ & $\begin{array}{l}\text { Aprox. } 3 \\
\text { salários } \\
\text { mínimos. }\end{array}$ & $\begin{array}{l}\text { Destruição da } \\
\text { moradia e da } \\
\text { propriedade rural, } \\
\text { desemprego. }\end{array}$ \\
\hline $\begin{array}{l}\text { F3: Casal, um filho em idade pré- } \\
\text { escolar, um filho em idade } \\
\text { escolar, uma filha adolescente } \\
\text { (amasiada). }\end{array}$ & $\begin{array}{l}\text { Ensino fundamental } \\
\text { incompleto. Ensino } \\
\text { fundamental completo } \\
\text { (adolesc) }\end{array}$ & $\begin{array}{l}\text { Autônomos (produção } \\
\text { caseira de salgados). } \\
\text { Costureira (adolesc) }\end{array}$ & $\begin{array}{l}\text { Aprox. } 2 \\
\text { salários } \\
\text { mínimos }\end{array}$ & $\begin{array}{l}\text { Perdas materiais da } \\
\text { moradia. }\end{array}$ \\
\hline $\begin{array}{c}\text { F4: Casal e uma filha adotiva em } \\
\text { idade escolar. }\end{array}$ & $\begin{array}{l}\text { Ensino fundamental } \\
\text { completo. Ensino médio } \\
\text { completo. }\end{array}$ & Agricultores & $\begin{array}{l}5 \text { salários } \\
\text { mínimos }\end{array}$ & $\begin{array}{l}\text { Mortes na familia, } \\
\text { perdas na produçãao } \\
\text { agricola. }\end{array}$ \\
\hline $\begin{array}{l}\text { F5: Casal, dois filhos em idade } \\
\text { escolar, um filho adolescente. }\end{array}$ & $\begin{array}{c}\text { Ensino fundamental } \\
\text { incompleto. Estudantes na } \\
1^{\mathrm{a}} \text { e } 5^{\mathrm{a}} \text { séries. Ensino } \\
\text { fundamental completo } \\
\text { (adolesc). }\end{array}$ & $\begin{array}{c}\text { Embaladores numa } \\
\text { fábrica local, inclusive o } \\
\text { adolescente. }\end{array}$ & $\begin{array}{l}\text { De } 5 . a 6 \\
\text { salários } \\
\text { mínimos }\end{array}$ & $\begin{array}{l}\text { Destruição da } \\
\text { moradia, } \\
\text { desemprego. }\end{array}$ \\
\hline F6: mãe e um filho lactante. & Ensino médio completo. & $\begin{array}{l}\text { Operadora de máquina } \\
\text { industrial. }\end{array}$ & $\begin{array}{l}\text { Aprox. } 3 \\
\text { salários } \\
\text { mínimos }\end{array}$ & $\begin{array}{l}\text { Perdas materiais, } \\
\text { desemprego. }\end{array}$ \\
\hline
\end{tabular}

\section{RESULTADOS E DISCUSSÃO}

A sequência de narrativas sobre a experiência da família 6 no desastre natural é apresentada a seguir, sendo paralelamente discutidos os achados sobre as demais cinco famílias do estudo. Tais narrativas representam as trajetórias típicas ao longo do período de transição, de onde emergiu a categoria de análise sobre as mudanças das rotinas familiares, possibilitando traçar as semelhanças e os contrastes entre os casos.

A história da família 6 é narrada por uma jovem mãe (MF6) que compõe, juntamente com seu filho lactente, um núcleo monoparental. Na época da ocorrência do desastre, ela residia com a família de origem, na respectiva área rural, e estava no segundo trimestre de gestação. A transição do desastre natural foi acompanhada da transição desenvolvimental pelo nascimento do primeiro filho, repercutindo em mudanças nas rotinas familiares. Assim também, as demais famílias apresentam pontos de mudança nas rotinas familiares ao longo da transição pelo desastre natural, com a influência de aspectos do ciclo vital na sua organização diária.

\section{$1^{\text {a }}$ trajetória: o período anterior ao desastre}

No sábado, a gente saiu pra dar uma volta e ver as coisas, porque estava todo mundo curioso, nunca tinha acontecido algo assim aqui (-). À noite já tinha caído uma casa aqui em cima e a mulher que morava lá morreu (-). A estrada já estava fechada e nós não 
tínhamos mesmo noção do que iria acontecer [...]. No domingo, a gente conseguiu retirar uma família da casa deles e a abrigou aqui em casa, porque nem a mulher nem o marido queriam sair da casa [...]. A nora dela é muito amiga da minha mãe e já estava aqui (-), nós fizemos um almoço e estava sem energia elétrica, então era tudo muito ruim [...] não tinha água, então a gente encheu uma piscina de fibra pra carregar água e poder, ao menos, lavar as louças (-). Até aí estava tudo normal, a gente achou que estava tudo indo bem. (MF6)

A narrativa revela que a rotina e os rituais típicos de um final de semana foram inicialmente afetados por condições imprevistas ao contexto da moradia, porém improvisaram para manter a normalidade de um almoço de domingo. No entanto, deslizamentos de terra foram sendo percebidos, chamando a atenção para os sinais de ameaça. De maneira semelhante, na família 3, a observação do volume das chuvas e do aumento no nível das águas do ribeirão culminou na decisão pela saída da mãe com as crianças de casa, em busca de local mais seguro. 0 pai, por sua vez, optou por permanecer na moradia, tomando medidas para minimizar perdas materiais, caso houvesse inundação. As narrativas dos outros casos mencionam que tais atitudes são rotineiras nas situações mais previsíveis nas enchentes em menor proporção. Neste sentido, estas rotinas representam parte de uma trajetória coletiva das famílias, no que se refere à busca de abrigo seguro e à ressonância dos sinais de alerta entre os moradores.

A trajetória que antecedeu os acontecimentos dramáticos narrados pelas famílias pode ser entendida sob um aspecto que corrobora para as tentativas de manutenção da regularidade da rotina na situação de ameaça. Semelhante a um estudo sobre o pós-terremoto-tsunami na Indonésia ${ }^{13}$, a magnitude de tantas perdas pode ser atribuída não somente ao tamanho do desastre, mas também à ausência de uma subcultura associada ao tipo de desastre. Assim como a comunidade afetada pelo tsunami não possuía mecanismos de resposta por desconhecerem tal fenômeno (ainda que os terremotos fossem já conhecidos na região), as famílias pesquisadas também narraram a falta de noção do que poderia acontecer, muito embora já incorporassem à sua rotina alguns comportamentos relacionados a experiências anteriores com pequenos alagamentos e inundações.

\section{$2^{\mathrm{a}}$ trajetória: a ocorrência do desastre (compreende três dias do acontecimento)}

Começou a cair umas barreiras ali para baixo e o pessoal começou a vir tudo pra cá. Na hora do desespero, a gente não sabia o que fazer. A nossa casa tinha umas cento e poucas pessoas (-), com todas aquelas machucadas de outra casa que desabou [...] Mas o pior foi na noite de domingo para a segunda-feira. A gente tinha passado 0 domingo inteiro aqui em casa e à noite fomos lá para o morro [...] mas naquela hora ninguém mais sabia o que era seguro. Lá a gente tinha feito uma barraca, levamos um fogãozinho, porque não tinha mais comida (-) nós já tínhamos dado o que tinha [...] e comemos lá em cima do morro, só que a água que a gente bebia era da chuva. Eu estava muito preocupada com a gravidez e ficava com muito medo de perder, principalmente depois que comecei a sentir muita dor, daí eu não conseguia mais andar (-). Na segunda-feira, conseguimos arrombar a porta da malharia aqui do lado [...] foi o jeito que arranjamos para pedir socorro. A gente teve que ligar três vezes para a Defesa Civil para que eles acreditassem que aqui tinha gente morta e gente ferida (-) e eles não acreditaram. Na segunda-feira, quando finalmente chegaram os helicópteros [...] sei que logo me levaram e minha mãe ficou. Eu queria que eles a tivessem levado comigo, mas não a deixaram, porque tiveram que levar todos os feridos por primeiro, depois eu que estava grávida, e as mães daquelas crianças mortas (-) e depois foram os senhores de idade, os mais novos e minha mãe veio bem depois. (MF6)

Esta trajetória mostra a ruptura da regularidade da rotina familiar diante da imprevisibilidade do desastre natural e a ocorrência de uma rotina atípica, voltada para suprir as necessidades básicas e tentar lidar com as adversidades causadas pelo evento. Nas demais famílias, foram narradas algumas atividades que fizeram parte da rotina durante 0 desastre, como exemplo, os pais de cada família (1,2 e 3) que auxiliaram a equipe de socorro na localização de vítimas e no resgate de corpos, ou buscando notícias sobre vizinhos nas casas em risco. No caso das famílias 4 e 5 , a saída abrupta e inesperada da moradia, o deslocamento para um local seguro e o acompanhamento do resgate de familiares vitimados desencadearam instabilidade e reações estressantes, afetando também o estado de saúde da jovem gestante na família 6 .

Ao mesmo tempo, protegiam e preservavam especialmente crianças, idosos e pessoas feridas, fornecendo alimentos e roupas secas que ainda restavam nas moradias em que se abrigavam e tentando amenizar o estresse das famílias mais atingidas. Este esquema de ação improvisado das famílias expressa um ponto importante da trajetória coletiva, o qual foi se delineando e se traduzindo num mecanismo natural de suporte social.

Na menção das famílias, um ponto dramático nas trajetórias individuais durante o desastre se relacionou à falta de credibilidade de outros atores sociais no momento em que 
foram solicitados pelas famílias em desamparo (no caso da família 5 , vizinhos resistiram em ajudar), e à falta de agilidade na resposta e socorro de órgãos governamentais, o que lamentavelmente pode ter favorecido o aumento do número de mortos.

A busca por local seguro junto de vizinhos caracteriza o breve período da ocorrência do evento como uma trajetória coletiva, em que as rotinas se unificaram em meio às incertezas circunstanciais. Rotinas são bastante fidedignas ao índice de colaboração, acomodação e sinergia familiar, ${ }^{14}$ e seus membros usualmente não percebem as inúmeras acomodações que regularmente fazem dentro do domicílio, equilibrando simultaneamente as limitações e recursos, adaptando continuamente as demandas relacionadas ao contexto, aos processos de interação funcional da unidade doméstica e às necessidades particulares de cada membro ${ }^{10}$. Neste sentido, é possivel perceber que os sucessivos acontecimentos levaram a uma ruptura da rotina habitual das famílias envolvidas, com algumas adaptações que visavam fundamentalmente à sobrevivência.

\section{$3^{\text {a }}$ trajetória: período inicial pós-desastre e passagem nos abrigos (dos primeiros seis meses até um ano e dois meses pós-evento)}

Como fui direto para o hospital, não dei entrada em abrigo nenhum. [...] Estavam levando os parentes para lugares diferentes, todo mundo ficou separado. Depois encontrei meus irmãos e ficamos juntos, mas logo vieram nossos parentes nos buscar para ficar na casa deles. Rotina não existia [...] porque a gente se mudava de vez em quando [...] é difícil se acostumar com os costumes de outra familia e em duas semanas acho que nem se consegue isso. (MF6). A rotina que eu tinha era ir ao médico, trabalhar, e só. Estas outras coisas que agora a gente faz com a família, a gente não tinha (-), não tinha nem cabeça para fazer outras coisas. (MF6)

A permanência nos abrigos dificultou ou impediu o restabelecimento das rotinas familiares que organizavam a vida antes do desastre. Foram necessárias tentativas de adaptação aos horários e ao modo de realização das tarefas diárias nos abrigos públicos, assim como habituar-se ao "ritmo" e à referência cultural das rotinas nas casas dos familiares, além da criação de novas rotinas como frequentar os centros distribuidores de doações em alimentos e roupas, dentre outras.

A imprevisibilidade permeava o cotidiano, mostrandose fator estressante à rotina das famílias, uma vez que muitas delas haviam perdido a moradia e outros bens materiais, além de familiares, vizinhos e amigos com quem conviveram na localidade. A necessidade de gerar renda para recuperar 0 perdido e também para ter alguma ocupação mobilizou alguns membros dos núcleos familiares 1, 2, 3, 5 e 6 na busca de trabalho, porque aqueles que não perderam seus empregos permaneceram afastados temporariamente, organizando uma rotina familiar nestas condições, com flexibilização no cumprimento de tarefas parentais e maior colaboração entre os membros.

A pouca previsibilidade nas rotinas familiares e as mudanças culminaram no adoecimento das crianças, hospitalizações e episódios dramáticos, como as tentativas de suicídio de um membro da família 3. As condiç̃es estruturais dos abrigos temporários e a irregularidade nas rotinas de cuidado às crianças, especialmente quanto aos horários e ao preparo das refeições, foram os principais motivos levantados pelas famílias 2 e 3 no que se refere ao adoecimento e à necessidade de assistência médica aos filhos pequenos.

Por outro lado, na trajetória subsequente que foi marcada pelo longo período em que as famílias do estudo permaneceram deslocadas de seu contexto de vida anterior ao desastre, e também pelos episódios associados à passagem pelos abrigos, as rotinas familiares foram acomodadas às regras institucionais e, em alguns casos, às regras das famílias acolhedoras. Nesse sentido, a acomodação das rotinas é entendida como um esforço de toda a família para adaptar, contrabalancear ou reagir a algumas forças contraditórias em suas vidas, mas não somente em resposta a estressores ou problemas, ocorrendo também quando os membros são motivados a alcançar metas particulares ou algo que tenha prioridade significativa naquele momento ${ }^{10}$.

Algumas situações culminantes como 0 adoecimento das crianças foram relatadas nesta trajetória, tendo em vista a alteração nos padrões de comportamento individual, nas condições de cuidado e nas rotinas familiares diárias. Segundo um estudo, há relação entre a ruptura nas mudanças de vida e seus efeitos sobre as rotinas familiares e a severidade da doença na criança. Principalmente em famílias muito ritualizadas, tais efeitos tornam as crianças mais estressadas do que protegidas pelas suas rotinas que foram afetadas ${ }^{15}$. Dois aspectos ressaltados pelas famílias merecem atenção sobre a sua implicação na estabilidade e na previsibilidade das rotinas familiares, os quais foram comprometidos na experiência dos abrigos: os padrões de tempo e o espaço simbólico. 0 tempo influencia o modo com que as rotinas familiares são estruturadas e priorizadas; além do mais, o tempo está ligado às percepções e aos ritmos que variam entre os membros de uma mesma família e entre famílias dentro de um contexto cultural ${ }^{8}$. Ademais, "a coletivização das rotinas no abrigo depõe contra a construção social da família e das identidades de seus membros" ":128. Todavia, as famílias buscam seguridade emocional e intimidade quando criam uma dinâmica particular ao espaço (sala de aula, por exemplo) que ocupam nos abrigos temporários, onde tentam reproduzir um lar, as rotinas neste ambiente "privado" apropriado simbolicamente ${ }^{9}$. 


\section{$4^{a}$ trajetória: o recomeço (marco temporal que variou entre as famílias)}

Eu fui morar sozinha, na minha casa, em outubro, no ano seguinte ao desastre. Eu comecei a trabalhar de novo (-) hoje estou em outra empresa (-), mas está bom agora, porque estou registrada, conseguindo as minhas coisas [...]. Eu fui morar sozinha com meu filho, mas no início a minha irmã sempre ia dormir comigo todos os dias, porque eu não dormia sozinha (-) eu tinha medo. Eu ainda tinha muito medo quando a gente voltou pra cá [...]. A gente pensou nesta coisa de um dia sair daqui e ir morar em outro lugar, mas em todo lugar a gente corre riscos, né? (-) Mas agora, assim, está normal (-) a gente tem que ficar aqui (-) e não aconteceu mais nada também. [...] 0 que mais mudou pra nós é a questão de ônibus (-) tem um só que passa ao meio-dia e volta às dez da noite (-). O postinho que já era para estar aberto e que pra nós faz falta, porque pra gente ir até o município vizinho é muito longe (-) então, ou a gente paga particular ou tenta em outro município. (MF6)

0 recomeço representa o início de uma nova fase familiar, marcada, de modo geral, pela decisão familiar em tocar a vida para frente e buscar recursos externos e internos para retornar à comunidade ou para migrar. No caso da família 4, o significado de dar continuidade à vida diz respeito à reconstrução de laços após as várias perdas familiares.

A reconstrução e a aquisição das moradias é uma das tarefas que mais influencia nas rotinas familiares desta fase, assim como as incumbências econômicas e sociais consequentes a ela, mas retomar seu espaço próprio e reconquistar a autonomia na organização das atividades diárias fornece maior previsibilidade e regularidade à vida familiar. 0 retorno ao trabalho e a aquisição de um novo emprego, no caso de alguns cônjuges e de filhos adolescentes, são atividades que garantem a renda e que orientam o estabelecimento de horários, regras e divisão de tarefas no convívio diário familiar. As famílias 1 e 3 narraram suas preocupações em manejar os diferentes horários de trabalho entre os cônjuges às atividades escolares e de cuidado das crianças, ainda contando com as situações imprevistas na rotina escolar dos filhos que, eventualmente, sofre mudanças pela ocorrência de alagamentos e fortes chuvas (por exemplo, cancelar dias de aula, modificar o calendário de férias ou liberar as crianças mais cedo para casa), as quais exigem dos pais acionar a sua rede mais próxima de apoio.

0 medo da recorrência de um desastre é presente na rotina de todas as famílias do estudo, com maior ou menor importância dada pelos seus membros. No caso das mães das famílias 1 e 3, o medo traz angústia e insegurança, interferindo na organização da rotina nos dias de chuva e também na atenção e proteção destinada aos filhos. 0 abandono do emprego pela mãe da família 3 foi influenciado pela experiência traumática no desastre e levou a mudanças na rotina.

As famílias também narraram sobre as mudanças percebidas nas rotinas de antes e após o desastre, as quais estão também relacionadas às fases e tarefas do ciclo de vida, por exemplo, as rotinas direcionadas à introdução e ao acompanhamento dos filhos na escola (família 1), ao nascimento de um bebê (família 6), às demandas sociais e educacionais dos filhos adolescentes (famílias 2, 3, 5), ao adoecimento crônico de um cônjuge (família 2) ou à morte acidental de membros da família ampliada no pós-desastre (famílias 3 e 5). A chegada da criança, após a gravidez da adolescente, implica a redefinição das relações familiares e, em algumas famílias, a superação de dificuldades financeiras e conflitos familiares ${ }^{16}$, aliada à tarefa desenvolvimental do cuidado.

É importante que profissionais da saúde e de enfermagem reconheçam que as trajetórias familiares que expressam os processos de evacuação, de recuperação e de reconstrução diferem de acordo com a dimensão dos danos causados pelo evento. A reorganização na estrutura familiar, em especial quando há muitas perdas, pode ser mais dramática e faz submergir o quão fundamental é a família como unidade social de apoio e a ajuda da rede mais próxima nesta fase de transição $0^{13}$.

0 recomeço contou com a plasticidade na condução de tarefas entre os membros das famílias, de modo que as suas rotinas promovessem 0 alcance das metas particulares a esta fase.

Rotinas familiares são afetadas pelo contexto ecológico ${ }^{10}$, o que pode ser percebido, no pós-desastre, pelas mudanças no cenário ambiental, social e econômico narradas pelas famílias deste estudo.

A literatura ${ }^{17,2-4}$ reforça que mulheres, crianças e adolescentes são mais propensos a manifestar sintomas de estresse pós-traumático e depressão em consequência a um desastre natural, repercutindo na saúde mental e nas relações/ conflitos familiares. Os resultados de um estudo pós-tsunami mostraram que mães em sociedades tradicionais ficam mais vulneráveis aos impactos dos desastres naturais do que os pais, devido ao seu elevado compromisso com as funções de cuidado na família, ao menor suporte social e poucos serviços disponíveis, às grandes perdas e poucos recursos, além das adversidades enfrentadas após o evento negativo de vida. Este estudo sugere que os estressores secundários ao desastre (falta de roupas, de comida, o desemprego, perda de recursos e da moradia) promovem efeitos adicionais aos problemas de saúde posteriores ${ }^{5}$. No caso das crianças, quanto mais o tempo passa após o evento, mais os pais precisam estar atentos às reações de seus filhos, fornecendo alguma estrutura para as suas rotinas diárias e suporte para seu bem-estar². Pais traumatizados podem manifestar maiores preocupações com 
a segurança das crianças no pós-desastre, e a superproteção pode estar associada à ansiedade e ao medo, em especial das mães, assim como conflitos transitórios podem ocorrer quando os membros da família vivenciam este processo diferentemente ${ }^{17}$. De modos específicos, os pais e as mães da presente pesquisa expressaram alguma influência de suas preocupações e medos com relação à segurança dos filhos na organização das rotinas diárias.

Estágios do ciclo vital também afetam as rotinas familiares, ao passo que a cultura, a etnicidade, a raça ou as características familiares também são confrontadas pelos aspectos previsíveis do desenvolvimento ${ }^{10}$. Embora 0 desenvolvimento individual varie de acordo com a idade, características e experiências dos membros, o desenvolvimento familiar também resulta em resposta às necessidades desenvolvimentais dos indivíduos, como em um processo de "maturação sistêmica"10:167. Envolvidas na complexidade do dia a dia da vida familiar, rotinas e rituais fornecem um contexto para o desenvolvimento da criança ${ }^{18}$, e isto parece ter sido um esforço dos pais em toda a trajetória pós-desastre, recuperando gradativamente os recursos vinculados à vida dos filhos (brinquedos, o quarto de dormir, as atividades de lazer, o retorno à escola, etc).

\section{$5^{a}$ trajetória: a vida atual no pós-desastre}

Daí conheci o (atual companheiro), a gente está há seis meses juntos, e ele aceita muito o meu filho [...] ele me ajuda muito. Então agora é eu, ele e o meu filho que moramos na minha casa [...]. De manhã estou em casa e trabalho das 13:30 às 22, em uma fábrica [...] Quando chego, o meu filho já está dormindo e está na casa dos avós [...], aos sábados eu também trabalho então ele fica na casa da minha sogra das 9 até às 13 horas. Nos finais de semana, a gente sempre está juntos. Ele [o companheiro] trabalha na geral, das 7 às 17 horas. O que eu penso, hoje, é deixar uma boa coisa para o meu filho, um bom estudo (-) o que eu não pude ter, embora eu ainda queira estudar (-), mas eu quero voltar a estudar na hora que eu terminar de pagar a casa. (MF6)

Um aspecto importante observado nos dados colhidos através do Calendário de Rotinas se deve a todas as famílias terem registrado ou comentado que a rotina do dia a dia não muda, ou que é sempre a mesma durante a semana. Isso nos leva a inferir na ritualização das rotinas diárias, principalmente marcadas pela rotina de trabalho que rege a realização das demais atividades como momentos de encontro, hora de dormir e de acordar, horário e duração das refeições, saídas para fazer compras ou para ir ao posto de saúde, à distribuição e organização das tarefas conforme o gênero (quem cuida das crianças, quem prepara o café, quem ajeita as camas), com a educação dos filhos para a participação e a colaboração na rotina doméstica e de manutenção do lar.

No que tange à trajetória atual, ou seja, um ano após o desastre, estudos originários sobre o referencial teórico definiram que é por meio da estrutura das rotinas que as famílias criam uma realidade social em que a estabilidade e a continuidade de suas vidas coletivas são afirmadas e mantidas ${ }^{19}$. A ideia de normalidade do dia a dia no pós-desastre, expressada pela maioria das famílias do estudo, identifica-se com a descrição de rotinas caracterizadas por uma regularidade mais previsível e a percepção de certa estabilidade dos aspectos contextuais influentes na organização da vida. Entretanto, as rotinas têm elementos dinâmicos (características individuais, fatores domésticos e valores dos membros) e por isso podem ser modificadas. Além disso, as mães são as principais condutoras, mantenedoras, promotoras das rotinas e cuidadoras dos membros e da unidade familiar ${ }^{10}$, cuja observação foi enfática no presente estudo.

\section{CONSIDERAÇÕES FINAIS}

Retomando o objetivo deste artigo, que foi de discutir as rotinas diárias de famílias rurais com crianças, nas trajetórias de transição pela ocorrência de um desastre natural, pretendese salientar a importância do contexto em que se desenrolam as mudanças de vida e o impacto delas nas rotinas para a organização e o funcionamento de cada família. Embora tenham sido consideradas as trajetórias individuais de cada família estudada, as experiências narradas mostram aspectos comuns e coletivos nestas trajetórias, apontando-nos as similaridades das situações dramáticas vividas e das transições para a nova fase pós-desastre.

Os resultados deste estudo também trazem a ideia de que a cultura e a identidade de tais famílias rurais, ao desejarem ser independentes ou não esperarem a solução dos problemas por outros, revelam-se um indicador para o estabelecimento de rotinas no pós-desastre, com centralização no trabalho e na demanda das novas tarefas que motivam o recomeço. Ademais, cultura e etnicidade compõem o cerne das rotinas familiares, 0 que é reforçado pela literatura e referencial teórico utilizados.

As contribuições deste estudo direcionam-se em especial aos profissionais de enfermagem que lidam com populações na situação de pós-desastre, mas estende-se a toda a equipe de saúde da família. Entretanto, a enfermagem foi pouco mencionada pelas famílias, que ao narrarem episódios em que necessitaram de algum atendimento, interpretaram a atitude de alguns enfermeiros e técnicos de enfermagem despreparados e insensíveis diante da situação dramática vivida pelas famílias.

É de fundamental importância que sejam incluídos ou, mais especificamente, abordados nos currículos dos cursos de 
enfermagem no Brasil os conteúdos referentes à promoção da saúde de populações atingidas por desastres naturais. Recomenda-se que outras pesquisas ampliem o conhecimento sobre as rotinas pós-desastre de famílias com outras configurações e etapas do ciclo vital, e que sejam exploradas as relações de gênero nas rotinas de cuidado à saúde no pósdesastre e também a relação com a rede de suporte social. Há uma lacuna de conhecimento que precisa ser preenchida para que práticas e políticas de atenção à saúde na situação de desastres sejam efetivas no cenário brasileiro; para tanto, pesquisas futuras devem explorar as experiências dos profissionais de saúde da família e as estratégias de atenção e de cuidados promovidos no pós-desastre.

\section{REFERÊNCIAS}

1. Denny P, McFetridge B. The Impact of Disaster on Culture, Self, and Identity: Increased Awareness by Health Care Professionals is Needed. Nurs Clin North Am. 2005 sep; 40: 431-44

2. Coffman S. Children's Reactions to Disaster. Journal of Pediatric Nursing. 1988 Dec; 13(6): 376-82.

3. Murray JS. Responding to the Psychosocial Needs of Children and Families in Disasters. Crit Care Nurs Clin North Am. 2010 Dec; 22(4): 481 91.

4. Rowe CL, Liddle HA. When the levee breaks: treating adolescents and families in the aftermath of Hurricane Katrina. J Marital Fam Ther. 2008 Apr; 34(2): 132-48.

5. Wickrama T, Ketring SA. Change in the health of Tsunami-exposed mothers three years after the natural disaster. Int I Soc Psychiatry. 2012 May; 58(3): 278-88.

6. Wickrama KAS, Wickrama KAT. Family contexto f mental health risk in Tsunami affected mothers: Findings from a pilot study in Sri Lanka Soc Sci Med. 2008 Feb; 66(4): 994-1007.

7. Mulvihill D. Nursing care of children after a traumatic incident. Issues in Comprehensive Pediatric Nursing. Issues Compr Pediatr Nurs. 2007 Jan/ Jun; 30(1-2): 15-28.

8. Valêncio N, Siena M, Marchezini V, Gonçalves IC. Sociologia dos desastres: construção, interfaces e perspectivas no Brasil. São Carlos(SP): RiMa Editora; 2009. V.2

9. Valêncio N. Sociologia dos Desastres. Construção, interfaces e perspectivas no Brasil. v. II. São Carlos(SP): RiMA Editora; 2010.

10. Denham S. Family Health. A Framework for Nursing, [s.I]: F. A. Davis Company; 2003.
11. Cerveny CMO, Berthoud CM. Família e Ciclo Vital: nossa realidade em pesquisa. São Paulo(SP): Casa do Psicólogo; 1997.

12. Schütze F. Pesquisa biográfica e entrevista narrativa. In: Weller V, Pfaff N. Metodologias da Pesquisa Qualitativa em Educação. Teoria e Prática. Petrópolis(RJ): Vozes; 2010.

13. Takahashi M, TanakaS, Kimura R, Umitsu M, Tabuchi R, Kuroda T, Ando M, Kimata F. Restoration after the Sumatra Earthquake Tsunami in Banda Aceh: Based on the Results os Interdisciplinary Researches by Nagoya University. J nat. disaster sci. 2007 jun/dec; 29(2): 53-61.

14. Denham SA. Family Routines: a construct to considering family health. Holist Nurs Pract. 1995 jul; 9(4):11-23.

15. Boyce WT et al. Influence of Life Events and Family Routines on Childhood Respiratory Tract Illness. Pediatrics. 1977 oct; 60(4): 609-15.

16. Hoga LAK, Borges ALV, Reberte LM. Razões e reflexos da gravidez na adolescência: narrativas dos membros da família. Esc Anna Nery. 2010 jan/mar; 14(1): 151-7.

17. Caruana C. Life in the Aftermath. Family Relationships Quartely. 2009; 14: 3-7.

18. Spagnola M, Fiese BH. Family Routines and Rituals. A Context for development in the Lives of Young Children. Infants young Child. 2007; 20(4): 284-99.

19. Boyce EWT, Jensen EW, James SA, Peacock JL. The Family Routines Inventory: theoretical origins. Soc Sci Med. 1983; 17(4): 193-200.

\section{NOTA}

${ }^{\text {a }}$ Resultado de tese de doutorado defendida em novembro de 2011 